\begin{tabular}{|l|l|l|l|l|}
\hline Revista Jangwa Pana & ISSN: 1657-4923 & Vol. 13 & 166 - 178 & Enero - Diciembre de 2014 \\
\hline
\end{tabular}

\title{
EL PATRIMONIO COMO ESPACIO DE CONFLICTO EN BARICHARA, SANTANDER
}

\section{HERITAGE AS A SPACE OF CONFLICT IN BARICHARA, SANTANDER}

\author{
Luz Andrea Cote Navarro ${ }^{1}$
}

\begin{abstract}
RESUMEN
A través del análisis del caso de Barichara, este texto pretende reflexionar sobre la conflictividad propia del campo del patrimonio cultural, los fundamentos de las tensiones que en él se dan y el papel que en ello ha venido a cumplir la noción de patrimonio inmaterial. Así mismo, busca llamar la atención sobre la necesidad de atender los impactos socioculturales de los procesos de patrimonialización. Para ello se identifican los principales actores y ámbitos de conflicto del campo patrimonial específico de Barichara, así como los criterios y nociones implicados en estas tensiones. El artículo deja en evidencia la necesidad de replantear la idea de Barichara como patrimonio cultural esencial e inmutable, para asumir la complejidad de una cultura viva.
\end{abstract}

Palabras clave: patrimonialización, campo, patrimonio inmaterial, conflicto, oficios artesanos

\begin{abstract}
Through the analysis of the case of Barichara, this paper aims to make a reflection about the conflictual nature of cultural heritage field, the causes of their tensions and the role that intangible heritage concept has come to play for them. It also seks to draw attention to the need to assist the sociocultural impacts of heritagization processes. For that, we identified the main actors and boundaries of conflicts in the specific heritage field of Barichara, the same as the criteria and notions involved in these tensions. The article evidences the need to rephrase the idea of Barichara as an essentially immutable cultural heritage to assume the complexity of a live culture.
\end{abstract}

Keywords: patrimonialization, field, immaterial heritage, conflict, craftmanship

Tipología: Articulo de reflexión

Fecha de recepción: 24/01/2014

Fecha de aceptación: 27/06/2014

Como citar éste artículo: Cote, L. A. (2014). El Patrimonio como espacio de conflicto en Barichara, Santander. Jangwa Pana, 13, $166-178$

1. Universidad de Barcelona: Doctorado en Gestión de la Cultura y el Patrimonio - Laboratorio de Patrimonio y Turismo Cultural (LAB-PATC). España. Correo: luzcote@gmail.com. 


\section{INTRODUCCIÓN}

$\mathrm{C}$ omo señalan diversos autores, el patrimonio cultural se ha intentado presentar desde el ámbito institucional como un espacio de consenso, un escenario en el cual desaparecen los conflictos y afloran los acuerdos en cuanto a la identidad de una sociedad (García Canclini, 1982, 1999; Miceli, 1987; Prats, 1997; Agudo, 2005, Quintero, 2005; Arrieta, 2010). Esta noción puede considerarse derivada de los criterios de legitimación propios del romanticismo que presentan el patrimonio como esencial e inmutable, y de la asociada utilización de monumentos artísticos y arquitectónicos para la creación o afirmación de nacionalismos (Anderson, 1993; Prats, 1997).

A partir de la década del sesenta la noción tradicional de patrimonio, y su modelo de gestión, comienzan a flaquear como consecuencia de los cuestionamientos que surgían tanto en el seno de las instituciones tutelares del patrimonio, como en la sociedad general, a raíz de los procesos de descolonización, los nuevos enfoques de la antropología que superaban la idea piramidal de civilización, la constatación de una visión eurocentrista en la gestión del patrimonio cultural y las demandas sociales de reconocimiento a la diversidad cultural (Agudo, 2005; Carrera, 2005; Arrieta, 2010). Así mismo, la proliferación de patrimonios en los procesos de construcción de identidades locales (Duclos, 1997), y la creciente industria turística que encontró en el patrimonio cultural un nuevo recurso a aprovechar (MacCannell, 2003; Valcuende del Río, 2003; Frigolé \& Roigé, 2010), llevarían a los antropólogos a trasladar la atención del objeto patrimonial a la patrimonialización, entendiendo el patrimonio cultural como una construcción social que deja entrever las luchas, tensiones e intereses que se esconden detrás de la institucionalización de unos determinados objetos o manifestaciones como símbolos de grupos sociales (Prats, 1997; Arrieta, 2010; Davallon, 2010; Frigolé \& Roigé, 2010). Como consecuencia, diversos autores proponen asumir el patrimonio cultural como un espacio de conflicto, que debe ser estudiado desde la perspectiva de las luchas materiales e ideológicas que en él se dan (García Canclini, 1999; Carrera, 2005; Arrieta, 2010).

El concepto de patrimonio cultural inmaterial vendría a acentuar la conflictividad del ámbito patrimonial porque supuso el replanteamiento de los criterios de valoración del llamado "patrimonio material", amplió las fuentes de producción y validación de los bienes patrimoniales, $\mathrm{y}$, de esta manera, complejizó el panorama de actores involucrados en los procesos de patrimonialización (Kirshenblatt-Gimblett, 2004; Carrera, 2005; Quintero, 2005; Arizpe, 2008).

A través del análisis del caso de Barichara, este texto pretende reflexionar sobre la conflictividad propia del campo del patrimonio cultural, los fundamentos de las tensiones que en él se dan y el papel que en ello ha venido a cumplir la noción de patrimonio inmaterial. Así mismo, busca llamar la atención sobre la necesidad de atender los impactos socioculturales de los procesos de patrimonialización. El artículo deviene de una investigación para la maestría en Gestión del Patrimonio Cultural de la Universidad de Barcelona y visitas posteriores a Barichara, estudio fundamentalmente cualitativo en el que se realizaron tres trabajos de campo con cerca de 60 entrevistas. A ello se suman varios años de conocimiento del área de estudio por parte de la autora.

\section{La patrimonialización de Barichara}

En 1750, cerca del Pueblo de Indios de Móncora -en el actual departamento de Santander-, sobre una variante del antiguo camino real, en una altiplanicie que constituía un lugar de paso para los indígenas guane, se erigió Barichara como una parroquia de blancos ${ }^{2}$. Pese al intento de separación entre pueblos de indios y parroquias de blancos, las prácticas y técnicas de ambos grupos se mezclaron, como sucedió con la tapia espa-

2. Los vecinos del sitio consiguieron el reconocimiento como viceparroquia en 1741 . 
ñola y el bahareque indígena (Sánchez, 2007), y la incorporación del telar europeo a las técnicas guane de tejido de algodón y fique (Bayona \& Raymond, 1987).

Estas prácticas se conservaron, en parte, porque Barichara quedó aislada en 1940 cuando el camino real dejó de utilizarse debido a la construcción de la Vía al Mar (Arenas, 1997). Posiblemente contribuyó a este aislamiento el hecho de que se prolongara en la zona el período de "La Violencia" hasta la década del setenta, en forma de enfrentamientos entre familias.

En 1975, el periodista Hernando Giraldo escribió un reportaje sobre Barichara que daría inicio a su apelativo de "el pueblo más bonito de Colombia" (Silva, 2001:123). Al año siguiente, llegó allí el entonces presidente Alfonso López Michelsen para celebrar los cien años de la presidencia de Aquileo Parra, quien fuera oriundo de Barichara. El hecho fue reportado por diversos medios de prensa, llevando imágenes del municipio a todo el país. En 1978, el centro histórico (CH) de Barichara sería declarado Monumento Nacional ${ }^{3}$ -actualmente Bien de Interés Cultural (BIC) de carácter nacional-.

Posteriormente se llevó a cabo la pavimentación de la ruta que comunica a Barichara con San Gil y la Vía al Mar, suma de factores que favoreció la llegada de visitantes, algunos de los cuales convirtieron al pueblo en lugar de residencia (Silva, 2001).

\section{El nuevo proyecto patrimonial y turístico de Barichara}

En la actualidad, las guías turísticas de Barichara resaltan el conjunto general de su $\mathrm{CH}$. En consonancia, los habitantes perciben que la principal motivación de quienes visitan el pueblo es la arquitectura "tradicional" y los sitios históricos que en él se encuentran. No obstante, cada vez

3. La declaratoria se dio mediante el Decreto 1654, de 1978. Una anterior resolución del Ministerio de Educación, de 1975, había hecho ya este nombramiento, pero había resultado inoperativo. más la promoción turística, los habitantes y los visitantes hacen énfasis en otro aspecto: la cultura local, especialmente los oficios artesanos. En ello enfatiza también la Red Turística de Pueblos Patrimonio de Colombia, a la que se vinculó Barichara desde $2010^{4}$.

Este perfil patrimonial y turístico de Barichara se ha retroalimentado con la presencia de aquellas personas del ámbito cultural que comenzaron a llegar desde la década de 1980. Entre los "nuevos vecinos", llamados "tierrafueras" por algunos baricharas, una cuota importante la constituyen artistas, arquitectos, catedráticos universitarios, educadores e investigadores. También personalidades retiradas de la vida política de Colombia. Algunas de estas personas comenzaron a desempeñarse como gestores culturales y otras han asumido principalmente un rol de mecenas, para lo cual han creado instituciones sin ánimo de lucro. Se trata de personas con importante capital económico, social y/o cultural, y, en algunos casos, con poder político para desempeñar roles determinantes en el escenario local.

Entre las instituciones creadas que más se destacan a nivel local y nacional, se encuentran la Fundación San Lorenzo de Barichara, la Fundación Escuela Taller de Barichara, la Fundación José María Delgado - Papá Chepe y la Fundación Tierra Viva. Sus acciones en materia de patrimonio se han centrado en la investigación, formación y fomento de algunos oficios artesanos considerados tradicionales en el pueblo, como forma de apoyo al desarrollo local.

Se ha configurado así un panorama en el que valores tangibles e intangibles se encuentran fuertemente vinculados. Frigolé \& Roigé (2010:22) identifican como un fenómeno común a los destinos turísticos rurales el uso de las nuevas ideas del mundo rural en nuevos mercados, que permiten vender las cualidades tangibles e intangibles del espacio rural "reconceptualizadas" en tres formas principales: turismo, urbanización y

4. Ver: < http://www.pueblospatrimoniodecolombia.travel/> 
demanda de productos conectados con la naturaleza. El caso de Barichara presenta tal característica en la medida en que su nombre se asocia a ideas de tradición, identidad e historia santandereana, redundando ello en un crecimiento del turismo, demanda de primeras o segundas residencias, y la consolidación como pueblo productor de artesanías.

Pero este nuevo proyecto sociocultural, político y económico basado en la asociación turismo patrimonio no se da en un espacio de consenso. Como señala Frigolé (2006), para el desarrollo de esta nueva economía se hace necesaria la "etiqueta de tranquilidad", la cual, paradójicamente, genera fuertes divisiones internas relacionadas con las nuevas perspectivas de desarrollo económico, el control del capital que la nueva etapa demanda y el liderazgo de la misma (Frigolé, 2006:27).

\section{Hacia un modelo de "política cultural de mecenazgo"}

El patrimonio cultural no corresponde a la cultura misma en la que vive la gente día a día, sino a unos elementos que son seleccionados y utilizados para representarla. En coherencia con esta idea, García García (2008) y KirshenblattGimblett (2004) señalan que las capacidades, teorizaciones y medidas referidas al patrimonio inmaterial operan en un plano metacultural (cultura que habla de la cultura), al margen de las culturas a las que se refieren. Una consecuencia de esto es que las medidas que se toman respecto del patrimonio inmaterial constituyen acciones principalmente simbólicas, lo que deviene en la disconformidad de los grupos interesados en mantener y proyectar sus prácticas culturales que perciben amenazadas.

Entre los distintos agentes de Barichara, son generalizadas las manifestaciones de decepción y escepticismo respecto de las instituciones e instrumentos relacionados con el patrimonio cultural, y su baja injerencia a nivel de local. Una de sus principales insatisfacciones tiene que ver con los exiguos resultados que ha dado el reconocimiento de Barichara como BIC nacional, en cuanto a medidas de fortalecimiento de la cultura local. No se aprecia una utilidad clara de la abundante normativa que se ha generado para favorecer a los municipios que tienen declaratoria de BIC. El Ministerio de Cultura y la Dirección de Patrimonio son vistas como entidades meramente policivas, enfocadas en la vigilancia de los proyectos de intervención del $\mathrm{CH}$.

Otro de los programas que ha creado el Gobierno nacional y que tiene presencia en el municipio de Barichara es el de Vigías del patrimonio que busca involucrar a la sociedad civil en la gestión del patrimonio cultural de la nación. En Barichara existen posiciones encontradas respecto de sus resultados: mientras algunos consideran que fueron positivos, otros creen que la conformación del grupo de vigías respondió a intereses de agentes que querían "bajar" recursos públicos.

A nivel de planificación municipal, el patrimonio cultural y la cultura son considerados temas relevantes -en particular los oficios artesanos. Los últimos tres planes de desarrollo incluyeron líneas de acción, programas y proyectos relativos a la "cultura", parte de los cuales han sido implementados. Sin embargo, las propuestas respecto de lo que se debe implementar, en general se esbozan como ideas y no como medidas concretas ${ }^{5}$. La Alcaldía local explica esto por la escasez de recursos económicos y de personal, con una Oficina de Cultura, Turismo y Deportes que con un presupuesto limitado debe hacer frente a los tres ámbitos. El Consejo Municipal de Cultura de Barichara debiera hacer seguimiento a los planes de desarrollo, sin embargo, dado que su conformación y su funcionamiento dependen de la alcaldía, la entidad no cuenta con iniciativa e independencia suficiente como para efectuar dicha labor.

5. Por ejemplo, El Plan de Desarrollo 2008-2011 incluye proyectos como: "Fomento de la cultura y el turismo", "conservación y divulgación del patrimonio cultural", "apoyo órganos informativos culturales" o "Capacitación a Guías de Turismo", entre otros. Como "metas", se cuantifican las propuestas, así: "5.000 personas beneficiadas en campañas de Conservación y divulgación del patrimonio cultural", aunque no queda claro en qué consistirá tal beneficio ni cómo se logrará concretar. 
Por su parte, los artesanos se quejan porque no cuentan con apoyo para consolidar los talleres e infraestructuras donde desarrollan su trabajo. Más aun, sienten que ciertas medidas legislativas amenazan la continuidad de sus oficios, que paradójicamente son exaltados como patrimonio cultural. Es el caso de los "chircaleros" que deben asumir ciertos cambios en su proceso de producción porque la legislación ambiental no permite el uso de hornos de leña o carbón. La vereda El Guayabal, donde hay 60 "chircales", está en proceso de buscar alternativas, pero los costos de los hornos de gas, y la falta de abastecimiento de gas propano licuado en Barichara dificultan la tarea (Santos \& Malagón, 2009). Por otra parte, la vereda está en proceso de catalogación como zona minera, lo que supone la aplicación de nuevas regulaciones.

Pero el caso al que más se hace referencia en el día a día de Barichara es el de la arquitectura en tierra, dado que la norma de construcción en Colombia no contempla la tierra como material de construcción. Esto no se traduce en la prohibición de edificar con este material ${ }^{7}$, pero sí fomenta el uso de otros materiales y restringe el acceso a fondos de vivienda social. En consecuencia, las personas con menores recursos no cuentan con subsidios públicos para viviendas de tapia o bahareque (Battistelli, 2005:11).

Se espera que el Plan Especial de Manejo y Protección $(\mathrm{PEMP})^{8}$ dé soluciones a estos vacíos, sin embargo, hubo una baja participación social en su proceso de elaboración y, por ello, la postura de los baricharas es escéptica. El texto final aún no se encuentra a disposición para consulta.

6. "Chircales" se llama en Santander a ladrilleras artesanales. En el caso de Barichara producen sobre todo teja de barro.

7. Las nuevas construcciones de Barichara que se levantan en tapia pisada cuentan con una licencia de construcción expedida por la Alcaldía municipal (Rivero, 2007:356).

8. El Plan Nacional de Recuperación de Centros Históricos (Mincultura, 2007) indica que los municipios BIC deben presentar un PEMP que debe incluir componentes como la importancia simbólica de los $\mathrm{CH}$ para sus habitantes.
En este escenario local, donde los instrumentos regulatorios y de planificación no se traducen en acciones concretas sistemáticas en materia de patrimonio inmaterial, las organizaciones sin ánimo de lucro creadas por los "nuevos vecinos" cobran una amplia maniobrabilidad, estructurándose lo que García Canclini \& Bonfil han denominado un modelo de "política cultural de mecenazgo"9 (1987:29-30). Mientras la administración municipal se siente limitada de presupuesto y personal para sacar adelante sus propuestas, las gestiones de los mecenas permiten realizar obras y acciones de envergadura, lo cual a su vez desata algunas controversias entre ambas partes. Los proyectos puestos en marcha por los mecenas son bien recibidos por algunos grupos sociales y criticados por otros. Algunos gestores culturales, por ejemplo, denuncian las rupturas que ciertas propuestas de innovación en técnica artesanal suponen respecto de la cultura local y la sostenibilidad de los oficios. A su vez, entre los barichara existe inconformidad porque consideran que muchas acciones no son pertinentes para al ámbito local, con enfoques elitistas y que dejan el mayor usufructo simbólico y económico para los organizadores.

No obstante, la mayor inconformidad de baricharas respecto al papel preponderante que juegan estos "nuevos vecinos", es que su rol se extiende a la vida cotidiana del pueblo, en la que se han instituido en veedores de la cultura local. Aun así, según la percepción de los baricharas, tienen a su vez el poder para contravenir las normas sin ser sancionados.

9. De acuerdo con García Canclini, en un modelo de "política cultural de mecenazgo": El desarrollo de la cultura no es visto como una cuestión colectiva (...) sino como el resultado de relaciones individuales: es una decisión personal la de financiar ciertos gastos culturales y elegir a quién se dará el dinero (...) Puede pensarse, desde una concepción actual de lo que deben ser las políticas culturales, que el mecenazgo no llega a serlo porque no se organiza en relación con las necesidades colectivas. Suele reducirse a la alta cultura y no pretende fijar estrategias globales para resolver los problemas del desarrollo cultural. Sin embargo, consideramos al mecenazgo una forma de política cultural porque ha servido y sirve en varios países para normar las relaciones en este campo, distribuir fondos importantes, establecer líneas prioritarias de crecimiento y desestimar otras (García Canclini \& Bonfil, 1987:29-30). 


\section{Disensos en cuanto a símbolos de identidad colectiva}

En los procesos de patrimonialización, personas o colectivos se asumen como herederos de un "mundo de origen", al cual están conectados a través de objetos o manifestaciones culturales. Esto ocurre mirando desde el presente al pasado, por eso Jean Davallon $(2002 ; 2010)$ habla de "filiación invertida"10. A los bienes, se les asigna valor patrimonial en función de "un proyecto, personal o colectivo, económico o cultural" (Frigolé, 2010:33). A su vez, para lograr la "activación patrimonial" hacen falta unas ciertas capacidades y poderes (Prats, 1997:33). Así por ejemplo, muchas manifestaciones culturales rurales han conseguido su reconocimiento como patrimonio en buena parte porque son demandadas por las clases sociales altas (García Canclini, 1999). De hecho, el concepto de "cultura tradicional" se utiliza con frecuencia para distinguir aquello de la "cultura popular" que ha calado en las élites culturales y económicas (Díaz Viana, 1999: 13).

En Barichara, hoy, el patrimonio cultural se define desde diversos agentes interesados y con capacidad de acción en esta temática: los "nuevos vecinos", incluidas las instituciones externas que operan en torno al patrimonio local; los agentes públicos que perfilan un proyecto patrimonial $\mathrm{y}$ turístico; y los propios baricharas, incluidos los artesanos, "portadores" de patrimonio inmaterial.

Así, en los procesos de patrimonialización en Barichara ha influido, en gran medida, la labor de instituciones creadas por los "nuevos vecinos" las cuales, en convergencia con agentes públicos, contribuyeron con investigación, formación y fomento de los oficios artesanos. En el año 2005, se emitió un acuerdo municipal que institucionalizaba el "Día del Patrimonio Cultural Patiamarillo"11, formalizando así un proceso de

10. Davallon toma el concepto prestado de Jean Pouillon.

11. Si bien el gentilicio es "barichara", los nativos se denominan a sí mismos "patiamarillos" por el color de la tierra arcillosa de la región. patrimonialización de los oficios artesanos, sustentado en una narrativa que apela a un "origen guane" y un "pasado colonial" de dichos ofi$\operatorname{cios}^{12}$. El proceso continuó con la asignación de la categoría de "Patrimonio Patiamarillo" al sistema constructivo de la tapia pisada en 2006. Esta tradición es considerada "típicamente baricharense", dado que los inmuebles antiguos construidos en tapia se encuentran en un excelente estado de conservación a la vez que se trata de un oficio vivo en Barichara. Además, se basa en una materialidad ligada al territorio, ya que utiliza madera, tierra y piedras de la zona como principales insumos.

La talla en piedra es otro oficio definido como "típicamente baricharense", conformando, junto con la tapia, el "patrimonio constructivo" local (Battistelli, 2005:40). La piedra también es utilizada para construir calles, cercas, y -desde el siglo XX- esculturas, artesanías y ornamentación para casas y fincas, con la incorporación de nuevas tecnologías y diseños.

La fabricación de tejas artesanales en "chircales" es otro oficio basado en técnicas artesanas tradicionales reconocido como BIC local. El Decreto de designación especifica que "la teja de barro es componente esencial de las casas que conforman el patrimonio histórico de Barichara".

La alfarería también es reconocida como patrimonio, tradición que se remonta a un pasado indígena y que todavía está presente en las veredas del corregimiento de Guane, dentro del municipio de Barichara, donde algunas mujeres mayores continúan elaborando "tiestos" de barro de manera artesanal. Inspiradas en esta tradición, instituciones como la Fundación Escuela Taller Barichara han emprendido diversas iniciativas de formación y transferencia tecnológica para la elaboración de cerámica bajo nuevos criterios de calidad e innovación en diseño.

12. Como señala Prats (1997), la historia y el pasado son fuentes importantes de "sacralidad" en el patrimonio. 
El tejido del fique es otro oficio que encuentra su validación patrimonial en la tradición guane. Durante los siglos XIX y XX, estuvo orientado a la confección de sacos, pero con la masificación de las fibras sintéticas, el uso del fique perdió relevancia a partir de los años ochenta y sólo es continuado por unas pocas familias en Barichara (Atelier, 2010). Se ha intentado revitalizar e innovar en este oficio, aunque con problemas de autosostenibilidad.

Como se puede ver, en tres de los cinco oficios mencionados hasta aquí - tejido del fique, alfarería y talla en piedra- se han impulsado innovaciones en los últimos años o décadas, manteniendo un vínculo con el "mundo de origen" a partir de una continuidad en los materiales utilizados, más que en las técnicas. Estas iniciativas provocan el surgimiento de nuevos artesanos en Barichara, incluso llegados de otras zonas del país, que entran es disputas de legitimación con los artesanos locales.

Además de los oficios patrimonializados, hay otros que pese a estar activos y formar parte de la historia local, no han sido dotados de los mismos discursos identitarios ni de valor patrimonial. Es el caso, entre otros, de la carpintería, o la forja y herrería, cuya producción, incluso, tiene actualmente gran demanda por su cercana relación con la construcción y ornamentación de nuevas viviendas.

El Instituto Técnico Aquileo Parra y la Escuela Taller Barichara han dictado cursos de forja y ornamentación, sin embargo, quienes practican este oficio sienten que no se le da la misma importancia que a otros: "Nos han tenido un poco olvidados. Igual la forja también ha sido un oficio tradicional. Inclusive más que la piedra en Barichara, o al mismo nivel. La cerámica si es mucho más antigua, por los indios"13.

13. Entrevista a Mario Carvajal, artesano de forja y ornamentación, Barichara 2012.
Otros oficios artesanos, como la elaboración de sombreros de Jipi-Japa, perdieron fuerza hasta desaparecer del pueblo en las últimas décadas del siglo XX, sin ser objeto de mayores esfuerzos de recuperación por la gran dedicación de trabajo y la poca rentabilidad que suponían.

La selección de ciertos oficios y la exclusión de otros como patrimonio de Barichara ha sido influenciada por las versiones de identidad de los locales, las versiones de ruralidad de los "nuevos vecinos", el despliegue de estrategias de las instituciones para legitimar su autoridad y la emergencia de un proyecto de desarrollo basado en lo turístico-patrimonial, entre otros factores. Esos diversos intereses en juego en algunos casos se confrontan, generando tensiones respecto de lo que constituye o no patrimonio de Barichara.

Como ejemplo de esto último, es común que los nuevos habitantes indiquen "la tranquilidad" y "el silencio" como valores intangibles del pueblo, mientras los lugareños también destacan la "tranquilidad", pero no asociada al silencio sino a la "seguridad" y la "familiaridad" entre los vecinos. Enfatizan que lo más importante en su cultura local son las "costumbres" y la "alegría" que piensan que ahora están siendo constreñidas por los nuevos residentes.

Darley Bueno, Secretario de Planeación Municipal, considera que fue un error no tomar medidas para proteger las "costumbres" y "tradiciones" de los habitantes cuando Barichara fue declarado Monumento Nacional, ya que los "tierrafueras" llegaron al pueblo pensando que éste sería como una postal, es decir, bello, sin gente y sin ruidos, y así quieren proyectarlo.

En definitiva, los nuevos vecinos se esfuerzan porque Barichara mantenga un carácter rural y apacible, sin la contaminación acústica que ha afectado a otros pueblos patrimoniales. Las tensiones se acentúan porque han logrado en muchos casos imponer sus intereses a través de acciones 
legales, modificando la cotidianidad local ${ }^{14}$. Los lugareños y el gobierno local consideran que los nuevos habitantes ejercen influencias para que las medidas que se toman desde el nivel nacional les favorezcan y se consolide un escenario adecuado a sus expectativas.

\section{De Monumento Nacional a Patrimonio Vivo}

De acuerdo con Victoria Quintero (2005:75), aunque es arbitrario separar patrimonio material e inmaterial, este último concepto sirve para resaltar los valores de los bienes patrimoniales, descubrir significados que necesitan de la práctica para ser comprendidos y complejizar los mensajes que se transmiten sobre los bienes patrimoniales.

De acuerdo con los postulados de los organismos internacionales, el reconocimiento de los oficios artesanos dentro de la categoría del patrimonio cultural inmaterial está destinado a la valoración del conocimiento como parte fundamental del patrimonio de las sociedades, y de las formas de vida que lo aprovechan (Quintero, 2005:75), siempre sin perder de vista que el patrimonio inmaterial es "indisociable de sus universos sociales y materiales" (Kirshenblatt-Gimblett, 2004:62-63).

A pesar de la inconformidad con la protección de las costumbres locales, tanto habitantes de Barichara como gestores culturales e investigadores, indican que para referirse al pueblo es necesario hablar de una "cultura viva". Battistelli, por ejemplo, señala que el $\mathrm{CH}$ no es un bien relicto sino producto de un conocimiento que sigue vigente y es la columna vertebral de la cultura local: el saber constructivo de la arquitectura en tierra (Batistelli, 2005:6). A él, como ya mencionamos, van adosados otra serie de saberes en otros oficios también vigentes. De allí que arqui-

14. Los baricharas citan algunas costumbres que se han ido perdiendo: los gallos en los solares, la periodicidad tradicional de las campanadas de la iglesia, los villancicos en Navidad, la bocina de la "chiva" y las guaraperías. tectos raizales y foráneos resalten el valor que tiene Barichara por ser producto del trabajo mancomunado de personas dedicadas a oficios distintos y complementarios, es decir, una "construcción colectiva" $"$. Es por esto que tanto nativos como nuevos habitantes destacan el conocimiento o el saber-hacer como el punto central del valor de Barichara.

Otro de los principales argumentos para que los habitantes de Barichara se refieran a una cultura viva, es que no se ha dado plenamente una "villadeleyvización"16, como se le llama al proceso por el que los pueblos pierden sus habitantes nativos y se convierten en sitio vacacional de citadinos, de fiesta nocturna y calles transformadas en hileras de locales comerciales. En general, los habitantes de Barichara consideran que algo a resaltar es que los nativos siguen conformando el $80 \%$ de la población y el municipio aun no pierde su vocación residencial ${ }^{17}$. Así mismo, que a pesar del crecimiento de la afluencia turística en el municipio $^{18}$, el turismo aparece aun con una posición prudente en el panorama laboral, y el sector primario sigue siendo predominante ${ }^{19}$.

Ahora bien, así como la patrimonialización crea valores patrimoniales o simbólicos para los objetos o manifestaciones, crea también valores económicos (Frigolé \& Roigé, 2010). Paradójicamente, la sustracción del bien patrimonial del mercado y el reconocimiento de su valor simbólico, potencian un mercado de lo auténtico dotando a ciertos objetos o manifestaciones de referentes de importancia simbólica. Estos objetos o manifestaciones de comercializan como "patrimonio vicario" (Frigolé, 2010:37). Tal forma de generar valor económico no opera solo al nivel de bienes muebles, sino que puede poten-

15. Término utilizado por José Raúl Moreno, Presidente de la Fundación Tierra Viva, Barichara, 2012.

16. Aludiendo el proceso vivido por Villa de Leyva

17. En Barichara un $73.3 \%$ del suelo se destina a vivienda (Alcaldía de Barichara, 2008)

18. No se tienen datos exactos porque no existe ningún sistema de registro. 19. Según el "Plan de Desarrollo Municipal 2008-2011", la oferta de empleo en Barichara está representada principalmente por el sector primario, mayormente el sector Agropecuario (58.51\%) (Alcaldía de Barichara, 2008) 
ciar un territorio como destino turístico (Santana, 1997; Prats, 1997; Kirshenblatt-Gimblett, 2001; Luque, 2004).

Barichara se encuentra en un momento interesante porque, aun conservando una serie de valores materiales e inmateriales que lo constituyeron en destino, debe decidir hasta dónde llevar su crecimiento turístico, poblacional y urbanístico. Para parte de los habitantes locales, crecer está significando perder poco a poco valores intangibles como la tranquilidad, el tejido social y la familiaridad entre los habitantes, el paisaje circundante, el trabajo en equipo y conocimientos y técnicas de oficios tradicionales.

Por un lado, la llegada de nuevos vecinos y la compra de casas o terrenos por parte suya o de baricharas, tanto para el propio aprovechamiento como para la especulación ${ }^{20}$, derivó en una tendencia inflacionaria que ha provocado la salida de antiguos habitantes del $\mathrm{CH}$.

Así mismo, es manifiesta la preocupación por el crecimiento del traslado de otras actividades productivas a sectores como el de comercio y servicios, y especialmente al de la construcción, que actualmente es el segundo oferente laboral (27\%). El crecimiento de este sector se debe, por un lado, a la construcción particular de viviendas de nuevos residentes y de hoteles, y al desarrollo de proyectos urbanísticos de empresarios con intereses en la zona. Por otro, a los proyectos de vivienda social que devienen de la dificultad de los baricharas de adquirir vivienda.

Este crecimiento urbanístico, la normativización de la construcción y la llegada de arquitectos que individualizan sus obras, dificultan a Barichara mantener valor como "construcción colectiva". De la misma forma, aquella dinámica económica de autoabastecimiento, aprovechamiento de los recursos circundantes y circunscrita a lo local

20. El gobierno local explica que un alto porcentaje de la población (al menos el $70 \%$ ) vive en alquiler, y en el $30 \%$ restante se concentra la propiedad de las viviendas del casco urbano. que dio origen al espacio que hoy se valora como patrimonio cultural -y es constitutiva de su valor inmaterial-, parece inviable en el nuevo contexto, por lo que la única alternativa pareciera ser una especie de congelamiento del $\mathrm{CH}$, a manera de archivo cultural, lo cual entra en conflicto con dinámicas sociales locales.

También, como señalan el gobierno local, algunos arquitectos y tapieros, y otros habitantes, el auge urbanístico ha hecho que se introduzcan cambios tanto en las técnicas de la arquitectura en tierra como en los materiales (incorporando cemento y hierro, entre otros), los cuales se considera que restan a las cualidades y sostenibilidad de las construcciones, y al conjunto de Barichara. El sector de la construcción a nivel local presenta, entonces, una cierta división entre quienes son partidarios de intentar mantener la técnica tradicional y quienes justifican estos cambios por razones económicas, normativas y de seguridad.

En otros frentes, como la talla en piedra, se viven situaciones similares. La introducción de máquinas como la pulidora ha permitido a los artesanos de la piedra elaborar piezas de gran formato para el sector de la construcción, producir más y hacerse más rentables. Estas mismas innovaciones los obligaron a sacar sus talleres del casco urbano, les han representado enfermedades pulmonares y, para varios representantes del sector, han significado una pérdida de calidad y valor agregado para las obras.

Por su parte, la tejería tradicional, aunque es un oficio que también se ha fortalecido por el auge de la construcción, enfrenta el reto de la instalación en la vereda El Guayabal de una fábrica productora de teja y ladrillo, de propietarios foráneos.

En conclusión, Barichara tomó forma a partir de una economía local, de una productividad austera que puso a funcionar un engranaje de "chircales", canteras de piedra, tapiales, talleres de piedra y de forja, todo lo necesario para convertir 
la materia prima que brindaba el entorno en un lugar habitable. Fue esta economía y forma de vida materializada en un poblamiento la que obtuvo un reconocimiento en 1978 bajo el título de Monumento Nacional. Este valor simbólico dotó al pueblo de un valor económico que lo llevó a desarrollar un nuevo proyecto social, cultural, económico y político, el cual pone hoy a todos los actores implicados ante la necesidad y el reto de gestionarlo lo mejor posible para que aquello que le dio vida no muera.

\section{Reflexión final}

Las reflexiones anteriores nos permiten explicar por qué algunos autores proponen asimilar el ámbito del patrimonio cultural al concepto de "campo" de Pierre Bourdieu, y, a partir de allí, estudiarlo como un espacio de conflicto (Quintero, 2005; Arrieta, 2010; García Canclini, 1999).

De acuerdo con Bourdieu (1991), las condiciones de existencia están interrelacionadas con la acumulación, en formas diversas, de capital económico, cultural y social. La acumulación de cualquier tipo de capital tiende a funcionar como capital simbólico, en la medida en que le sea reconocido a quien lo detenta (Bourdieu, 1990).

Un campo es un espacio social específico y su estructura está determinada por la relación de fuerzas entre los agentes a su interior, es decir, por la distribución del capital específico acumulados en las luchas anteriores (Bourdieu, 1990:136). Se define, entre otras, a partir de objetos en juego e intereses específicos, distintos a los de otros campos (Bourdieu, 2000:112-113). Para que un campo funcione, es preciso que haya personas con el conocimiento y el reconocimiento de las leyes inmanentes al campo, dispuestas a participar del juego. Las luchas al interior del campo son luchas de legitimación. El capital específico, el que está en juego, es a la vez la condición de entrada, y el objeto y el arma de la actividad en dicho campo. Siempre se dará una lucha entre los recién llegados y los dominantes: los prime- ros tienden a desafiar la ortodoxia al interior del campo y los segundos tratan de mantenerla y excluir la competencia.

El campo patrimonial se ha estructurado a partir de los capitales, intereses, estrategias, etc., de una serie de agentes. Valcuende del Río (2003) señala que son las entidades públicas y privadas, técnicos, grupos sociales y turistas, entre otros, quienes han configurado el patrimonio cultural, cuyo sentido actual es el de representar la identidad:

La existencia de un campo implica que todos los agentes involucrados acepten su doxa, (...) en nuestro caso, que el patrimonio cultural y el conjunto de bienes culturales que lo constituyen simbolizan la identidad colectiva (...) En el juego de relaciones o en la lucha por hacerse con el control del campo patrimonial, los referentes identitarios pueden cambiar, pero, en todo caso, su configuración permanece idéntica, es decir, la vinculación del patrimonio y los bienes culturales con la identidad (Arrieta, 2010:306).

Toda versión de identidad es una construcción social en la que el patrimonio juega un papel fundamental por el acto de "reflexividad" (Davallon, 2010:57) que supone -en la medida en que el grupo debe construir una representación de sí mismo-, pero también como versión ya existente, o institucionalizada, de la identidad. El patrimonio participa como causa y efecto de la estabilidad identitaria, pero, al ser símbolo de distintas versiones de identidad, podemos entender por qué es un "campo de confrontación simbólica" (Prats, 1997:38).

En Barichara, el campo del patrimonio cultural es fértil para el conflicto porque se trata de una "cultura viva", es decir que las manifestaciones patrimonializadas no son relictas, sino que están en práctica y suponen una renovación permanente del conocimiento. Así mismo, la definición de la identidad local está atravesada por miradas supralocales representadas por instituciones públicas y privadas que hacen presencia en el muni- 
cipio, y especialmente por los "nuevos vecinos" que actúan como agentes culturales.

En el nuevo proyecto patrimonial y turístico que marca el derrotero para la sociedad de la Barichara actual, los disensos se dan sobre todo en cuanto a los aspectos de la cultura local que es necesario proteger, la forma de protegerlos y/o viabilizarlos, el espacio que se está dando a los cambios culturales, y la sensación, por parte de los baricharas, de una pérdida de control de las decisiones respecto a estos temas por causa del poder político y el capital económico, social y cultural de los "nuevos vecinos".

En este contexto es importante resaltar y profundizar algunos temas como las formas de legitimación que en esta dinámica de transformación están emergiendo tanto para ciertas manifestaciones culturales como para los llamados "portadores" del patrimonio cultural. Las disputas entre artesanos tradicionales y artesanos contemporáneos por la autoridad para investigar, ejercer y enseñar ciertos oficios, puede ayudar a ensanchar los conocimientos sobre los impactos de los procesos de patrimonialización y su asociación con el turismo.

Sobre Barichara se ha escrito bastante en espacios mediáticos o promocionales, destacando la belleza y armonía de su centro histórico, y, más recientemente, sus oficios artesanos. No obstante, es poco lo escrito desde las ciencias sociales sobre todas las implicaciones socioculturales que están suponiendo la construcción de discursos identitarios en un contexto de globalización, los procesos de patrimonialización de la cultura local y el crecimiento del turismo. Textos como el presente son sólo una invitación a continuar adelante con dichos estudios.

\section{REFERENCIAS BIBLIOGRÁFICAS}

Anderson, B. (1993). Comunidades Imaginadas. Reflexiones sobre el origen y la difusión del nacionalismo. México, D.F: Fondo de Cultura Económica. (Primera edición en inglés, 1983).
Agudo, J. (2005). Patrimonio etnológico: recreación de identidades y cuestiones de mercado. En Instituto Andaluz del Patrimonio Histórico \& Andalusia, Patrimonio inmaterial y gestión de la diversidad (pp. 197-213). Sevilla: Junta de Andalucía, Consejería de cultura.

Alcaldía de Barichara (2008). Plan de Desarrollo Municipal 2008-2011 Barichara somos todos, Barichara.

Arizpe, L. (2008). El patrimonio cultural inmaterial y el futuro. En Ruf Riba, M.A. (Coord). L'ànima de la humanitat, el patrimonio cultural inmaterial (p.p 103-115). Andorra: Universitat d'Estiu d'Andorra, Ministeri d'Educació i Cultura, Govern d'Andorra.

Arenas, E. (1997). El viaje, Bogotá: Cámara de Representantes, Capitolio Nacional.

Arrieta, I. (2010), El campo patrimonial y museístico: un espacio cultural conflictivo. En Revista de dialectología y tradiciones populares, vol. LXV, no 2, pp. 303-336.

Atelier, (2010). Fique, historia y futuro de una fibra vegetal, Bogotá.

Battistelli, A. (2005). Tecnología y patrimonio en tierra cruda en Colombia. El caso de Barichara en Santander. Italia: Politecnico di Torino.

Bayona, B., \& Raymond, P. (1987). Vida y muerte del algodón y los tejidos santandereanos. Bogotá: Ecoe.

Boltanski, L. \& E. Chiapello. (2002). El nuevo espiritu del capitalismo. Madrid: Akal.

Bourdieu, P. (1990). Algunas propiedades de los campos. En Sociología y cultura (pp. 135-141). México: Conaculta.

Bourdieu, P. (1991). El sentido práctico. Madrid: Taurus.

Bourdieu, P. (2000). Cuestiones de sociología. Madrid: Itsmo.

Carrera, G. (2005). La evolución del patrimonio (inter) cultural: políticas culturales para la diversidad. En Instituto Andaluz del Patrimonio Histórico \& Andalusia, Patrimonio inmaterial y gestión de la diversidad (pp. 16-29). Sevilla: Junta de Andalucía, Consejería de Cultura. 
Davallon, J. (2002). ¿Comment se fabrique le patrimoine?, Sciences humaines, ¿Qu'est-ce que transmettre?, Hors-série 36, mars-avrilmai, pp. 74-77. Recuperado de: http://www. scienceshumaines.com/comment-se-fabriquele-patrimoine fr 12550.html.

Davallon, J. (2010). The game of heritagitazion. En Frigolé, J. \& X. Roigé (Eds). Constructing cultural and natural heritage: parks, museums and rural heritage (pp. 39-62). Girona: Documenta Universitaria.

Díaz, L. (1999). Los Guardianes de la tradición: ensayos sobre la «invención» de la cultura popular. Sendoa: Oiartzun.

Duclos, J. (1997). Prólogo. En Prats, L. Antropología y patrimonio. Barcelona: Ariel.

Frigolé, J. \& X. Roigé (Coords). (2006). Globalización y localidad: perspectiva etnográfica, Barcelona: Publicacions i Edicions de la Universitat de Barcelona.

Frigolé, J. (2006). Globalización y producción de localidad en un valle del Alt Urgell. Modelo interpretativo y síntesis etnográfica. En Frigolé, J. \& X. Roigé. Globalización y localidad: perspectiva etnográfica (pp. 17-31). Barcelona: Publicacions I Edicions de la Universitat de Barcelona.

Frigolé, J. \& X. Roigé. (2010). Introduction. En Frigolé, J. \& X. Roigé (Eds). Constructing cultural and natural heritage: parks, museums and rural heritage (pp. 9-27). Girona: Documenta Universitaria.

Frigolé, J. (2010). Patrimonialization and the mercantilization of the authentic. Two fundamental strategies in a tertiary economy. En Frigolé, J. \& X. Roigé (Eds). Constructing cultural and natural heritage: parks, museums and rural heritage, (pp. 27-38) Girona: Documenta Universitaria.

García Canclini, N. (1982). Las culturas populares en el capitalismo. México: Editor Nueva Imagen/ Grijalbo.

García Canclini, N. \& G. Bonfil. (1987). Políticas culturales en América Latina. México, D.F.: Grijalbo.
García Canclini, N. (1999). Los usos sociales del patrimonio cultural. En Andalusia \& Instituto Andaluz del Patrimonio Histórico. Patrimonio etnológico: nuevas perspectivas de estudio (pp. 16-33). Andalucía: Consejería de Cultura, Junta de Andalucía.

García García, J. (2008). De la cultura como patrimonio al patrimonio cultural. En Política y Sociedad, no. 27, pp. 9-20.

Kirshenblatt-Gimblet, B. (2001). La cultura de les destinacions: teoritzar el patrimonio. En Revista d'Etnologia de Catalunya, no. 19, pp. 44-61.

Kirshenblatt-Gimblett, B. (2004). El patrimonio inmaterial como producción metacultural, Museum international, no. 221-222, vol. 56, no. 1-2.

Luque, I. (2004). ¿Proyectos patrimoniales o turísticos? Turismo y sociedad, vol. 3, pp. 62-70.

MacCannell, D. (2003). El Turista, Barcelona: Editorial Melusina (Primera edición en inglés, 1976).

Miceli, S. (1987). Estado, mercado y necesidades populares: las políticas culturales en Brasil. En García Canclini, N. \& G. Bonfil. Políticas culturales en América Latina (pp, 127-143). México, D.F: Grijalbo.

Mincultura. (2007). Plan Nacional de Recuperación de Centros Historicos (PNRCH), Bogotá. Recuperado de: http://www.mincultura.gov. co/?idcategoria=1328>, > [Consulta: 04/07/09]

Prats, L. (1997). Antropología y patrimonio, Barcelona: Ariel.

Quintero, V. (2005). El patrimonio intangible como instrumento para la diversidad cultural ¿una alternativa posible? En Instituto Andaluz del Patrimonio Histórico \& Andalusia. Patrimonio inmaterial y gestión de la diversidad (pp. 69-81). Sevilla: Junta de Andalucía, Consejería de cultura.

Rivero, S. (2007). El uso masivo de la tierra como material de construcción en Colombia. APUNTES, vol. 20, núm. 2, pp. 354-363.

Sánchez, C. (2007). La arquitectura de tierra en Colombia: procesos y culturas constructivas. APUNTES, vol. 20, núm. 2, pp. 242-255. 
Santana, A. (1997). Antropología y Turismo ¿Nuevas hordas viejas culturas? Barcelona: Ariel Antropología.

Santos, J. \& Malagón, P. (2009). Estudio de mejoramiento del proceso de fabricación de tejas y ladrillos con las arcillas de la vereda Guayabal del municipio de Barichara (Santander). Trabajo de Grado dirigido por PhD. Elcy María Córdoba Tuta, Universidad Industrial de Santander, Facultad de Ingenierías Físico Químicas, Escuela de Ingeniería Metalúrgica y Ciencia de Materiales, Bucaramanga.
Silva, E. (2001). Retazos históricos de mi pueblo Barichara. Barichara: Coomulseb.

Valcuende del Río, J. (2003). Algunas paradojas en torno a la vinculación entre patrimonio cultural y turismo. En Andalusia \& Instituto Andaluz del Patrimonio Histórico. Antropología y patrimonio: investigación, documentación e intervención (pp. 96-109). Sevilla: Consejería de Cultura, Junta de Andalucía, Comares. 